\title{
Clinical assessment of disease activity in rheumatoid arthritis: evaluation of a functional test
}

\author{
A A KALLA, ${ }^{1}$ T J v W KOTZE, ${ }^{2}$ O L MEYERS, ${ }^{1}$ AND N D PARKYN ${ }^{3}$
}

From the 'Department of Medicine, Rheumatic Diseases Unit, UCT; the 'Department of Medical Biostatistics, $M R C$, South Africa; and the ${ }^{3}$ Department of Information Technology, University of Cape Town

SUMMARY A cross sectional analysis of the correlation between clinical, laboratory, and radiological markers of disease activity in 98 patients with classical rheumatoid arthritis (RA) is reported. The median age was 38 years, the median age at onset of disease 29 years, and the median duration of disease seven years. The Keitel function test (KFT) showed good correlation with the Ritchie articular index (RAI) $(\mathrm{p}<0.0001 ; \mathrm{r}=0.5)$ and the disability questionnaire (DQ) $(\mathrm{p}<0.0001 ; \mathrm{r}=0.6)$. The RAI and DQ correlated weakly with laboratory variables, while the KFT showed significant correlation with the erythrocyte sedimentation rate (ESR), $C$ reactive protein (CRP), and plasma viscosity (PV) $(\mathrm{p}<0.001 ; \mathrm{r}=0.4 ; 0.3 ; 0.4)$. Only the KFT showed significant correlations with bone mass measurements $(p<0 \cdot 01 ; r=-0 \cdot 3 ;-0 \cdot 4)$, and the Larsen index at the right wrist $(\mathrm{p}<0.0001 ; \mathrm{r}=0.4)$. Consensus analysis suggested that the KFT is a useful single clinical test of disease activity in RA. The hand functional index (HFI), a component of the KFT, showed significant correlation with the total KFT $(r=0.9)$. Prospective drug trials are needed to establish the value of the HFI in the monitoring of patients with RA.

Key words: rheumatoid activity monitoring, hand functional index, Keitel function test.

The assessment of disease activity in rheumatoid arthritis (RA) is complicated by the overlap of process and outcome measurements. ' Since the systemic index of Lansbury (LSI) was published ${ }^{2}$ there have been many reports about its use, but hardly any comparisons with later indices. Numerous statistical approaches have been recommended in the interpretation of research. ${ }^{3-5} \mathrm{~A}$ 'weighted' articular index has recently been recommended for clinical use. ${ }^{6} \mathrm{~A}$ recent study introduces the concept of consensus analysis in evaluating changes in the natural history of the disease, comparing a number of laboratory markers. ${ }^{7}$ These reports outline the need for an all-encompassing clinical test of disease activity in RA.

Functional assessment is not a standard component of composite indices. ${ }^{8}$ The Steinbrocker classification of 1948 (American Rheumatism Association (ARA)) has been the standard reference of functional assessment in drug trials. ${ }^{9}$ The Keitel function test $(\mathrm{KFT})^{10}$ has been shown to have a high coefficient of generalisability in RA, ${ }^{\mathrm{i} i}$ but it has not

Accepted for publication 17 February 1988.

Correspondence to Dr A A Kalla. PO Box 195. Tokai 7966. Republic of South Africa. been studied as a marker of disease activity. It has been found to be a more reproducible method of clinical assessment than the Ritchie articular index (RAI), ${ }^{12}$ which is often a component of protocols evaluating drug treatment. ${ }^{13}$

Several attempts have been made to relate radiological changes to laboratory and clinical variables. ${ }^{14} 15$ The consensus seems to be that 'remission inducing' drugs improve clinical and laboratory variables ${ }^{16}$ but do not seem to influence radiological progression. ${ }^{14}$ Several reasons may explain this lack of correlation. The most obvious is that these variables are measuring different pathogenetic processes.

Against this background, a cross sectional study was undertaken to evaluate the correlation of measures of functional ability with clinical, laboratory, and radiological assessments of rheumatoid arthritis. Consensus analysis was used to find the most suitable functional test which would convey information regarding all these important changes of the disease.

\section{Materials and methods}

The protocol was approved by the research and 
ethics committee at the University of Cape Town. It was completed over a 12 month period. The study was confined to a premenopausal, young group of subjects who were independently ambulant, as age, ${ }^{17}$ menopause,$^{18}$ and physical activity ${ }^{19}$ have a significant effect on early radiological changes (osteoporosis), while laboratory changes (erythrocyte sedimentation rate (ESR)) are influenced by age. ${ }^{20}$

Ambulant patients with definite or classical $\mathrm{RA}^{21}$ under 50 years of age, who were attending the arthritis clinics of the rheumatic diseases unit at the University of Cape Town, were selected for study. A protocol was designed to record demographic data, menopausal status, duration of disease, criteria for classification of disease, work capacity, and family history of arthritis. Age at onset was taken as the time of first onset of symptoms of the disease. Patients were evaluated once only.

Disease activity was assessed clinically in several ways, by a single observer (AAK): (a) pain was recorded by the patient on a $10 \mathrm{~cm}$ visual analogue scale $^{22} ;(b)$ the patient similarly graded the severity of the disease on a $10 \mathrm{~cm}$ visual analogue scale; (c) duration of early morning stiffness ${ }^{23}$ was graded on a scale of $0-5$, where $0=$ less than 45 minutes, $1=45$ min-2 hours, $2=2-3$ hours, $3=3-4$ hours, $4=4-5$ hours, and $5=5$ hours or more; $(d)$ hours to onset of fatigue $^{23}$ were graded on a scale of $1-4$, where $1=$ less than 2 hours, $2=2-4$ hours, $3=4-6$ hours, $4=6$ hours or more, $(e)$ the presence or absence of night pain ${ }^{23}$ was recorded; $(f)$ warm and swollen joints were individually counted; $(g)$ the response to pain on pressure was recorded for the $\mathrm{RAI}^{12} ;(h)$ the mobility score ${ }^{24}$ was determined by a disability questionnaire (DQ), scaling the ease with which 24 activities of daily living could be carried out; $(i)$ the $\mathrm{KFT},{ }^{10}$ based on the observed performance of 24 tasks, was graded according to degree of performance by the patient; $(j)$ global assessment of disease activity was based on the physician's clinical findings and classed as nil, mild, moderate, and severe; $(k)$ the LSI $^{2}$ was calculated using the grip strength, duration of early morning stiffness and hours to onset of fatigue. The articular index and use of aspirin were not included in deriving the modified index. Grip strength was measured with the Mannefeldt manometer $(\mathrm{mmHg})$.

The KFT was arbitrarily divided, according to the major joints tested, into three groups of joints representing hands and wrists, shoulders, and lower limbs respectively. The hand and wrist component of the test, conveniently named the hand functional index (HFI), is shown in Appendix A.

Several laboratory measures of disease activity were simultaneously tested. The Westergren ESR $(\mathrm{mm} / \mathrm{h})$, C reactive protein $(\mathrm{CRP})(\mathrm{g} / \mathrm{l})$ (rocket electrophoresis), and plasma viscosity (PV) (centi poise) (capillary viscometer) were recorded fop? comparison with the above clinical markers. The modified LSI was calculated as described. Radiolo? gical evaluation was performed on both hands? radiographed at a tube distance of $100 \mathrm{~cm}$; exposure and development times were standardised for this study. Bone mass was calculated using a digitiser fo尺 measurement of inner and outer diameters at the midshafts of six metacarpals. The methods of Barnett and Nordin, ${ }^{25}$ Dequeker, ${ }^{26}$ Exton-Smitl et $a l^{27}$ and Horsman and Simpson ${ }^{28}$ were used ir $\vec{w}$ the calculation. The percentage cortical area and six metacarpal hand score were selected as the measures of bone mass as these are considered to be the most precise. ${ }^{2628}$ The carpometacarpal ratio was calculated by the method of Trentham and Masi. ${ }^{29}$ The right wrist was then graded for severity according to the modified index of Larsen et al. ${ }^{30} \mathrm{Al}$. radiological evaluations were performed by a single observer (AAK).

STATISTICAL METHODS

The data were recorded and checked on the IBM personal computer. These were then transcribed to the mainframe computer at the Biostatistics In tute (MRC), which was used for all the statistieapo calculations. The SAS package ${ }^{31.32}$ and BM statistics software ${ }^{33}$ were used for all the analysies Spearman rank correlations were calculated for the various clinical, laboratory, and radiological vario ables. The results of the ordinal (continuous) vari $\mathbb{\perp}$ ables only are reported as these are probably the most reliable. The respective correlations were cros\$ tabulated (correlation matrix), which provided eas visualisation of the rank correlation coefficient $(r)$ aș. well as the probability that the correlation was equad to zero ( $p$ value). The consensus value was the arithmetic average of the ranks of all tests other than the test under scrutiny. Consensus analysis was performed for the modified LSI, ESR, PV, an\& Larsen index at the right wrist.

\section{Results}

The study group consisted of 98 patients (28 male N 70 female), median age $38 \cdot 1$ years (range 18-50) and with a median duration of disease of seven years (range six months-28 years). The ESR (range $1-150^{\circ}$ $\mathrm{mm} / \mathrm{h}$ ) was raised in $63 \%$, the CRP (range 0-11. $\mathrm{g} / \mathrm{l}$ ) was raised in $60 \%$, and the PV (range $1 \cdot 39-3.0$ 里 cP) was raised in $80 \%$ of the patients at the time of study.

Table 1 shows the ARA classification of functionat disability ${ }^{9}$ as well as the UK functional classification. ${ }^{3}$ P In the same table the range for the total Keitel score? 
and DQ in the respective ARA and UK classes is also shown. It can be seen that there is a wide range of difficulty with activities of daily living, which are not detected in the narrow ARA or UK classification of disability.

The Spearman rank correlation matrix (Table 2) shows the correlation coefficient (r) in the upper triangular matrix and the $p$ value in the lower triangular matrix. The table shows that all the functional tests correlate significantly with the RAI $(\mathrm{p}<0.0001)$.

Table 3 examines the possible clinical usefulness of the three tests in evaluating disease activity. The DQ and KFT seem to differ in the way in which they relate to these other clinical tests of inflammation, particularly with respect to changes such as warmth or swelling of a joint, early morning stiffness, and hours to onset of fatigue. The LSI (a composite index of disease activity including ESR) correlated impressively $(p<0.0001)$ with the three clinical tests (RAI, DQ, KFT) $(\mathrm{r}=0.6 ; 0.6 ; 0.5$ respectively). When the ARA and UK functional classifications were compared with the same clinical variables as above, significant correlations were seen with all the tests.

Table 1 American Rheumatism Association (ARA) and UK functional classification of activities of daily living in 98 subjects with $R A^{*}$

\begin{tabular}{|c|c|c|c|}
\hline $\begin{array}{l}\text { Functional } \\
\text { classification }\end{array}$ & $n$ & $\begin{array}{l}\text { Range of } \\
K F T^{+}\end{array}$ & $\begin{array}{l}\text { Other tests } \\
(D Q)^{\dagger}\end{array}$ \\
\hline $\begin{array}{r}\text { ARA: } 1 \\
2\end{array}$ & $\begin{array}{l}22 \\
76\end{array}$ & $\begin{array}{r}5-40 \\
13-86\end{array}$ & $\begin{array}{l}0-51 \\
6-135\end{array}$ \\
\hline UK: $\begin{array}{l}1 \\
2 \\
3\end{array}$ & $\begin{array}{l}16 \\
34 \\
48\end{array}$ & $\begin{array}{r}5-40 \\
6-64 \\
18-86\end{array}$ & $\begin{array}{l}0-51 \\
0-99 \\
6-135\end{array}$ \\
\hline
\end{tabular}

*The more recent test of global disability (DQ) is shown for comparison.

$\dagger \mathrm{KFT}=$ Keitel function test; $\mathrm{DQ}=$ disability questionnaire.

Table 2 Correlation matrix showing relation between Ritchie articular index $(R A I)$, disability questionnaire $(D Q)$, and Keitel function test $(K F T)^{*}$

\begin{tabular}{llllll}
\hline & $R A I$ & $D Q$ & $K F T$ & $A R A$ & $U K$ \\
\hline RAI & & 0.6 & 0.5 & 0.5 & 0.6 \\
DQ & 0.0001 & & 0.6 & 0.6 & 0.7 \\
KFT & 0.0001 & 0.0001 & & 0.6 & 0.6 \\
ARA & 0.0001 & 0.0001 & 0.0001 & & 0.9 \\
UK & 0.0001 & 0.0001 & 0.0001 & 0.0001 &
\end{tabular}

*The correlation coefficient (r) is shown in the upper and the $p$ value in the lower triangular matrix (Spearman). Also shown are the comparisons with the older functional classifications (ARA, UK).
Table 3 Comparison of relations of Ritchie articular index $(R A I)$, disability questionnaire $(D Q)$, and Keitel function test (KFT) with standard clinical measures of disease activity in $R A$

\begin{tabular}{|c|c|c|c|c|c|}
\hline & & $R A I$ & $D Q$ & $K F T$ & $H F I^{*}$ \\
\hline \multirow[t]{2}{*}{ SVAS* } & $\mathbf{r}$ & $0 \cdot 3$ & 0.5 & 0.4 & $0 \cdot 2$ \\
\hline & p & 0.01 & 0.0001 & 0.0001 & 0.02 \\
\hline \multirow[t]{2}{*}{ PVAS* } & $\mathrm{r}$ & 0.4 & 0.5 & 0.2 & 0.05 \\
\hline & p & 0.0001 & 0.0001 & 0.03 & NS \\
\hline \multirow[t]{2}{*}{ Fatigue } & r & -0.4 & -0.3 & -0.3 & -0.1 \\
\hline & p & 0.0001 & 0.002 & 0.01 & NS \\
\hline \multirow[t]{2}{*}{ EMS* } & $r$ & 0.4 & 0.4 & 0.3 & 0.3 \\
\hline & p & 0.0001 & 0.0001 & 0.003 & 0.008 \\
\hline \multirow[t]{2}{*}{ Physician } & r & 0.5 & $0 \cdot 3$ & 0.4 & 0.5 \\
\hline & $\mathbf{p}$ & 0.0001 & 0.01 & 0.0002 & 0.0001 \\
\hline \multirow[t]{2}{*}{ Warm } & $\mathrm{r}$ & $0 \cdot 3$ & 0.2 & $0 \cdot 3$ & $0 \cdot 34$ \\
\hline & p & 0.01 & NS & 0.003 & 0.0004 \\
\hline \multirow[t]{2}{*}{ Swollen } & r & $0 \cdot 3$ & 0.2 & 0.4 & 0.5 \\
\hline & p & 0.001 & NS & 0.0001 & 0.0001 \\
\hline \multirow[t]{2}{*}{ LSI* $^{*}$} & $\mathrm{r}$ & $0 \cdot 6$ & 0.6 & 0.5 & 0.4 \\
\hline & p & 0.0001 & 0.0001 & 0.0001 & 0.0001 \\
\hline
\end{tabular}

${ }^{*} \mathrm{HFI}=$ hand functional index: SVAS=severity of disease on a visual analogue scale: $\mathrm{PVAS}=$ pain on a visual analogue scalc: EMS=early morning stiffness: LSI=Lansbury`s systemic index.

Table 4 shows the relations between the RAI, $\mathrm{DQ}, \mathrm{KFT}$, and the three standard laboratory markers of disease activity. The RAI correlated significantly with the ESR $(p<0 \cdot 05)$, but not with the CRP or PV. The DQ correlated significantly with the ESR $(p<0.01)$ and PV $(p<0.005)$, but not with the CRP. The KFT, on the other hand, correlated significantly with all three laboratory tests $(p<0.0001 ; p<0.002 ; p<0.0002)$. The HFI also correlated with all three laboratory tests of disease activity in RA.

Table 5 shows the correlation of RAI, DQ, and KFT with radiological markers. The RAI and DQ did not show a significant relation with any of the radiological markers used in this study. Although

Table 4 Comparison of relations of Ritchie articular index $(R A I)$, disability questionnaire $(D Q)$, and Keitel function test (KFT) with laboratory markers of disease activity and severity in $R A$

\begin{tabular}{|c|c|c|c|c|c|}
\hline & & $R A I$ & $D Q$ & $K F T$ & $H F I^{*}$ \\
\hline \multirow{2}{*}{\multicolumn{2}{|c|}{$\mathrm{ESR}^{*} \mathrm{r}$}} & $0 \cdot 2$ & $0 \cdot 3$ & 0.4 & 0.4 \\
\hline & & 0.02 & 0.01 & 0.0001 & 0.0003 \\
\hline \multirow[t]{2}{*}{ CRP $^{*}$} & $r$ & 0.2 & $0 \cdot 1$ & $0 \cdot 3$ & 0.3 \\
\hline & p & NS & NS & 0.002 & 0.01 \\
\hline \multirow[t]{2}{*}{$\mathrm{PV}^{*}$} & $\mathrm{r}$ & $0 \cdot 1$ & $0 \cdot 3$ & 0.4 & 0.4 \\
\hline & p & NS & 0.005 & 0.0002 & 0.0003 \\
\hline
\end{tabular}

${ }^{*} \mathrm{HFI}=$ hand functional index; $\mathrm{ESR}=$ erythrocyte sedimentation rate; $C R P=C$ reactive protein: $P V=$ plasma viscosity. 
the carpometacarpal ratio did not correlate significantly with any of the clinical tests $(p>0.05)$, the KFT was the only test which approached significance $(p<0 \cdot 08)$. The KFT was also the only test which showed a significant correlation with metacarpal bone mass and the Larsen index at the right wrist. In addition, the HFI showed more significant correlations with the above radiological markers than did the RAI or DQ.

The component Keitel scores correlated significantly with the total score $(p<0 \cdot 0001)$ (Table 6). The variation in the HFI explained the largest proportion of the variation in the total score $(r=0.873)$. In this group of subjects the HFI was able to predict over $75 \%$ of the variation in the total $\operatorname{KFT}\left(r^{2}\right)$.

Consensus analysis showed that the three clinical tests (RAI, DQ, KFT) ranked comparably against the LSI. The RAI was the weakest test in the ranking against the ESR, PV, and Larsen index at the right wrist. The KFT superseded the consensus value in each ranking process. The results of the comparison of RAI and KFT with the respective consensus is depicted in the histograms in Fig. 1.

Table 5 Comparison of the relations of Ritchie articular index $(R A I)$, disability questionnaire $(D Q)$, and Keitel function test (KFT) with metacarpal bone mass (CA\%, M6HS), * carpometacarpal ratio (CMR), and the Larsen index at the right wrist

\begin{tabular}{|c|c|c|c|c|c|}
\hline & & $R A I$ & $D Q$ & $K F T$ & $H F I^{*}$ \\
\hline \multirow[t]{2}{*}{$\mathrm{CA} \%$} & $r$ & $-0 \cdot 1$ & $-0 \cdot(0) 4$ & $-0 \cdot 3$ & $-0 \cdot 2$ \\
\hline & $p$ & NS & NS & $0 \cdot(0) 2$ & $0 .(15$ \\
\hline \multirow{2}{*}{ M6HS } & $r$ & $-0 \cdot 1$ & $-0 \cdot 1$ & $-0 \cdot 4$ & -0.2 \\
\hline & $p$ & NS & NS & $0 \cdot(0)(1) 6$ & $(0 \cdot() 2$ \\
\hline \multirow[t]{2}{*}{ CMR } & $r$ & $0 \cdot 1$ & $0 \cdot 01$ & $-0 \cdot 2$ & $-0 \cdot 1$ \\
\hline & p & NS & NS & 0.08 & NS \\
\hline \multirow[t]{2}{*}{ Larsen's index } & $\mathrm{r}$ & $0 \cdot 1$ & $0 \cdot 1$ & -0.4 & $0 \cdot 3$ \\
\hline & $\mathrm{p}$ & NS & NS & $0 \cdot 0001$ & 0.002 \\
\hline
\end{tabular}

${ }^{*} \mathrm{CA} \%=$ percentage cortical area: $\mathrm{M} 6 \mathrm{HS}=\mathrm{six}$ metacarpal hand score: $\mathrm{HFI}=$ hand functional index.

Table 6 Relation between the Keitel components and the total Keitel function test $(K F T)$ in the patients with $R A^{*}$

\begin{tabular}{lllll}
\hline & $H F I^{\dagger}$ & Shoulder & Lower limb & KFT \\
\hline HFI & & 0.5 & 0.4 & 0.9 \\
Shoulder & 0.0001 & & 0.4 & 0.7 \\
Lower limb & 0.0001 & 0.0001 & & 0.7 \\
KFT & 0.0001 & 0.0001 & 0.0001 & \\
\hline
\end{tabular}

${ }^{*}$ The correlation coefficient $(r)$ is shown in the upper and the $p$ value in the lower triangular matrix.

$+\mathrm{HFI}=$ hand functional index.

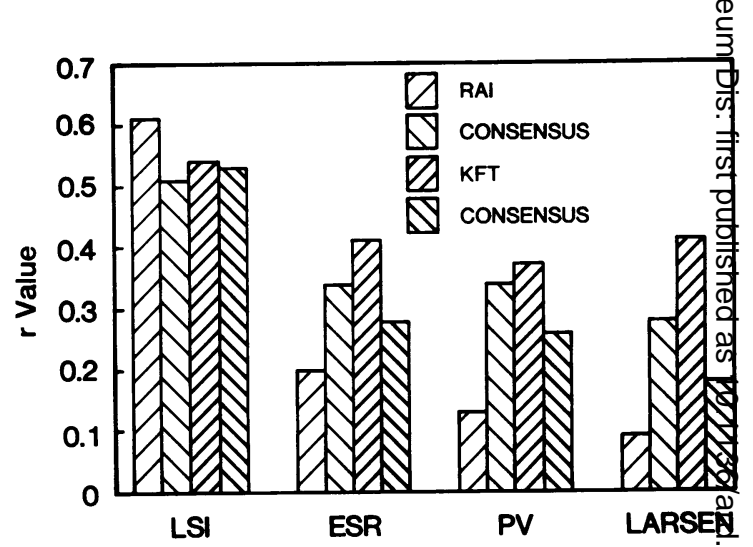

Fig. 1 Histograms showing the results of consensus analysis. The figure compares the relationship between the 6 $K F T$ and RAI and the respective consensus ranking derived from the RAI, KFT, DQ, and HFI. The tests were ranked $\omega$ with respect to the modified LSI, ESR, PV, and Larsen index at the right wrist. (KFT=Keitel function test; $R A I=$ Ritchie articular index; $D Q=$ disability questionnair $E$ $H F I=$ hand functional index; $L S I=L$ ansbury systemic index; $E S R=$ erythrocyte sedimentation rate; $P V=$ plasma viscosity.)

\section{Discussion}

It has been pointed out by several authors thas metacarpal bone mass is lost at a disproportionato rate in some individuals over the age of years. ${ }^{17} 2526$ The ESR is known to rise with age,, 2 which is one reason why the PV is recommended as a more objective marker of inflammator activity. ${ }^{35}{ }^{36}$ It has also been shown that functiona disability is greater in patients with longer duration of arthritis. ${ }^{93} .37$ For all these reasons it was com sidered essential to exclude patients over the age of 50 years and those who were severely incapacitate In this way the significance of correlations between variables need not be clouded by the confoundin effects of age and physical activity on laboratory and radiological variables.

The $\mathrm{LSI}^{2}$ needs to be modified for use in clinies such as ours, where salicylates are rarely used in the. management of RA. Use of a weighted articulag index is also complex and time consuming. The RAI $^{12}$ has been widely used for its simplicity ang was chosen as the articular index for this study. $\Psi \notin$ may be regarded as the 'gold standard' in clinici studies. Thermography is a reproducible technique of measuring activity in RA, ${ }^{38}$ but it is not general available for use in a busy practice. The ARA criteria for remission include the absence of fatigue, morning stiffness, and night pain. ${ }^{23}$ These variablo are relatively subjective, possibly making the 
unsuitable as markers of activity in RA, despite their wide clinical application. Also, physicians are known to be inconsistent in their clinical judgment of disease activity, ${ }^{39}$ and a simple, reproducible, meaningful clinical test is needed. When some of these 'external' tests were used, two thirds (or more) of our patients had active disease.

This seems to be the first comparison of the LSI with other disease activity markers (RAI). Ritchie et al showed good reproducibility between three observers, ${ }^{12}$ while other workers have been unable to reproduce the test adequately between observers. ${ }^{11}$ In fact, the RAI was recently modified to improve the interobserver reproducibility. ${ }^{40}$

Although the KFT was developed as a global measure of function in $\mathrm{RA},{ }^{10}$ and the $\mathrm{DQ}$ as a measure of mobility, ${ }^{24}$ it appears from Table 3 that these functional tests also measure disease activity. The significant correlation between the above tests (RAI, DQ, KFT) and the LSI suggests that they are all suitable markers of systemic disease. It is important to note that the HFI also correlated significantly with the LSI.

Although both functional tests (DQ, KFT) correlate significantly with the RAI, the tests are not predictive of each other $(\mathrm{r}<0 \cdot 8)$. The significant correlation between the RAI, DQ, and KFT confirms the clinical impression that active disease has a negative effect on functional capabilities. Caution is required in the interpretation of correlations where the dependent variable has a narrow range (ARA, UK functional classifications) as the predictive value $\left(r^{2}\right)$ may need to exceed $50 \%$ to be meaningful. The broader ranges of the KFT and DQ suggest that they may be suitable functional tests for comparison with the RAI, which is established as a clinical test of global disease activity in RA. It is interesting that the DQ and KFT not only test function but also give a significant reflection of disease activity. The ARA and UK functional classifications also show significant correlations with the RAI. They explain less of the variation in RAI than might be expected by chance, however.

Our findings of a good correlation between the KFT and RAI are the first such report. Although all three global tests showed good correlation with other clinical markers of disease activity in RA, it is interesting that the DQ did not correlate significantly with warmth or swelling of the joints. Table 3 shows also that the DQ reflected equally the patient's impression of severe disease and pain. while the KFT correlated more closely with the patient's impression of disease severity than pain.

Mielke and Deicher showed the limited significance of laboratory variables in assessing disease activity in RA. ${ }^{+1}$ The significant correlation between these clinical tests (RAI, DQ, KFT) and the ESR could be anticipated from the positive correlation with the LSI. The lack of correlation between the RAI and CRP confirms a recent report. ${ }^{7}$ The DQ also showed no significant correlation with the CRP, while the KFT correlated significantly with all three laboratory tests (Table 4). This suggests that the KFT may be a more useful global clinical test of disease activity than the DQ or RAI.

Several workers have commented on the lack of correlation between improvement in clinical and laboratory variables and radiological change in the same patients. ${ }^{1+15}$ Some of the difficulties in assessing disease activity radiologically may be due to the confusion in differentiating 'process' changes from 'outcome' measures. ${ }^{1}{ }^{42}$

Capell questioned the type of radiological changes used in evaluating drug responses in RA. ${ }^{+3}$ Scott and Bacon have shown that the erosion in RA is irreversible, except under unusual circumstances. ${ }^{1+}$ Buckland-Wright, using the technique of microfocal radiography, has shown that early erosions can be scored and monitored for change. ${ }^{44}$ Schorn has shown an increase in the metacarpal index with penicillamine treatment, confirming the sensitivity of bone mass measurement as a suitable end point for monitoring the effects of remission inducing drugs. ${ }^{+5}$

Table 5 shows that the RAI and DQ did not correlate significantly with any of the radiological variables recorded in this study. Our finding of an inverse relation between KFT and bone mass confirms the recent observation that bone mass falls with increasing disability, despite adequate ambulation. ${ }^{19}$ Although none of the three tests showed a significant correlation with the carpometacarpal ratio, the KFT came closest at the $10 \%$ level of confidence. The KFT was also the only test which showed a significant correlation with the Larsen index at the right wrist.

The KFT is an unacceptably time consuming test and not suitable for a busy clinic. When the test was subdivided into three component parts it was shown that in these subjects global involvement was common. The results showed that the total KFT could be adequately predicted by a test of hand function (HFI) alone $(r=0.873 ; p<0 \cdot 0001)$. This is a tremendous saving on the time taken to complete the full KFT, and is less than the time taken to perform the RAI or DQ. The preceding tables showed that the HFI correlated significantly with several clinical, laboratory, and radiological changes in RA. In a busy clinic time is often a limiting factor. The RAI can be performed within five to seven minutes, ${ }^{12}$ whereas the KFT requires about 12 minutes. ${ }^{10}$ The HFI is performed in less than one 
minute! It is, therefore, very suitable for clinical use, particularly as it correlates significantly with other disease activity markers.

When consensus analysis ${ }^{6}$ was used the KFT fulfilled several of the requirements for a clinical test of disease activity in RA: $(a)$ it was conveniently divided into component parts which show strong correlations with the total test score: $(b)$ of the three main clinical tests studied, it showed correlation with semiobjective tests such as the ESR, CRP, and $\mathrm{PV} ;(c)$ it correlated also with bone mass measurements and the Larsen index at the right wrist, suggesting that osteoporosis may be a significant end point in the radiological evaluation of the effects of remission inducing drugs in the treatment of RA, as suggested by Schorn et al. ${ }^{+5}$

Fries regards disability as an essential dimension in the measurement of outcome. ${ }^{+2}{ }^{46}$ Our findings suggest that the KFT is also a process variable. The sensitivity to change needs to be validated in prospective studies (analogous to earlier evaluations of change in RAI, ESR, CRP, and radiological abnormalities of RA) in drug trials. The first such study with auranofin was able to show significant improvement in KFT as one measure of outcome. ${ }^{47}$ Further studies are needed to establish the full potential of the HFI as a measure of outcome in RA.

The authors wish to express their thanks to $\mathrm{Sr}$ G M M Brown for recruiting patients and controls for this study. and also to Miss $\mathrm{R}$ van Wyk. of the MRC(SA), for the computer analyses of the data. This research was supported by the Arthritis Foundation (SA). the MRC (SA), and the Nellic Atkinson and Guy Elliott funds (University of Cape Town).

\section{Appendix A: Hand functional index (HFI)}

Test Items

1. Tip of thumb touches hypothenar of 5 th finger

2. Bending of 2 nd finger

...3rd,...4th....5th

fingers

6. Forearm held horizontal. 1 palmar surfaces pressed together point 2 upward

\section{Grading (riteria \\ Right Left \\ 0 () Test performed fully and with no delay}

Test performed fully but with effort or delay. or both

Tip of thumb touches proximal phalanx 3 and 4

Neither realised

Clutched normally

Cannot be bent fully; tip reaches palm

Fingertip does not reach palm

As above

Test performed fully and no delay

$2 \quad$ Test performed fully with effort or delay. or both

Volar and dorsal flexion of wrist $45^{\circ}$
7. Forearm held horizontal, 1 dorsal surfaces pressed together point downward

8. Both backs of hands simultancously on the 1 table: clbows held rectangularly; ulnar margin of hand lifted

9. Radial margins of hands () simultancously placed 1 on table; thumb points downward before table edge; planes of hands 2 inclined inward: no lateral bending of trunk

\section{References}

1 Fries J F. Spitz P W. Kraines R G. Holman H R. Measuremeo of patient outcome in arthritis. Arthritis Rheum 1980) 22: $137-45$.

2 Lansbury J. Haut D D. Report of a 3-year study on the systemic and articular indexes in RA. Arthritis Rheum 1958: 1: 505-29

3 McGuire R J. Wright V. Statistical approach to indices disease activity in RA - with reference to a trial of indomethP cin. Ann Rheum Dis 1971: 30: 574-80.

4 Mallya R K. Mace B E W. The assessment of disease activity RA using a multivariate analysis. Rheumatology and Rehahilit tion 1981: 20: 14-17.

5 Bombardier C. Tugwell P. A methodological framewor develop and select indices for clinical trials: statistical judgment approaches. J Rheumatol 1982: 9: 753-7.

6 Thompson P W. Silman A J. Kirwan J R. Currey H L Articular indices of joint inflammation in rhcumatoid arthrit Arthritis Rheum 1987: 30: 618-23.

7 Bull B S. Levy W C. Westengard J C, et al. Ranking laboratory tests by consensus analysis. Lancet 1986; 377-80.

8 Scott D L. Farr M. Hawkins C F. Wilkinson R. Bold A Serum calcium levels in rheumatoid arthritis. Ann Rheum DLs 1981: 40: 58(-3.

9 Steinbrocker O. Traeger C H. Batterman R C. Therapeutie criteria in rheumatoid arthritis. JAMA 1949: 140: 659-62.

10 Keitel W, Hoffman H, Weber G, et al. Ermittlung de prozentaulen funktionsminderung der Gelenke durch einem Bewengungfunktiontest in der Rheumatologie. Deutsche Gesundheitswesen 1971; 26: 1901-3.

11 Eberl D R. Fasching V. Rahlfs V. et al. Repcatability an objectivity of various measurements in rheumatoid arthritis: comparative study. Arthritis Rheum 1976; 19: 1278-86.

12 Ritchic D M. Boyle J A. McInnes J M. et al. Clinical studie with an articular index for the assessment of joint tenderness patients with RA. Q J Med 1968; 37: 393-406.

13 Rhind $\mathrm{V}$ M. Bird $\mathrm{H}$ A. Wright $\mathrm{V}$. A comparison of clinicab assessments of disease activity in RA. Ann Rheum Dis 1980: 39? $135-7$.

14 Scott D L. Bacon P A. Joint damage in RA: radiologic assessment and the effects of anti-rheumatic drugs. Rheumato Int 1985: 5: 193-9.

15 Scott D L. Grindulis A. Struthers G R. Coulton B L. Poper A J. Bacon P A. Progression of radiological changes rheumatoid arthritis. Ann Rheum Dis 1984: 43: 8-17.

16 Dixon J S. Wright V. Outcome measures and anti-rheumatic drugs: a critical appraisal. Clin Exp Rheumatol 1986: 4: 1-2. T

17 Avioli L. Age-related changes in bone mass. In: Aitken M, ed. Osteoporosis in clinical practice. Bristol, London: Wright, 1984 37-43. 
18 Van Soesbergen R M. Lips P, van den Ende A, van der Korst $\mathrm{J} \mathbf{K}$. Bone metabolism in rheumatoid arthritis compared with postmenopausal osteoporosis. Ann Rheum Dis 1986; 45: $149-55$.

19 Als O S, Gotfredsen A, Riis B J, Christiansen C. Are discase duration and degree of functional impairment determinants of bone loss in RA? Ann Rheum Dis 1985; 44: 406-11.

20 Shearn M A, Kang I Y. Effect of age and sex on erythrocyte sedimentation rate. J Rheumatol 1986; 13: 297-8.

21 Ropes M W, Bennett G A, Cobb S, Jacox R. Jessar R A. Revision of diagnostic criteria for rheumatoid arthritis. Bull Rheum Dis 1958; 9: 175-6.

22 Huskisson E C. Measurement of pain. Lancet 1974; ii: 1127-31.

23 Pinals R S, Masi A T, Larsen R A. Preliminary criteria for clinical remission in rheumatoid arthritis. Arthritis Rheum 1981: 24: 1308-15.

24 Badley E M, Wagstaff S, Wood P H N. Measures of functional ability (disability) in arthritis in relation to range of movement. Ann Rheum Dis 1984; 43: 563-9.

25 Barnett E, Nordin B E C. The radiological diagnosis of osteoporosis: a new approach. Clin Radiol 1960; 11: 166-74.

26 Dequeker J. Quantitative radiology: radiogrammetry of cortical bone. Br J Radiol 1976; 49: 912-20.

27 Exton-Smith A N. Millard P H, Payne P R. Whecler E F. Method for measuring quantity of bone. Lancet 1969: ii: 1153-4.

28 Horsman A, Simpson $M$. The measurement of sequential changes in cortical bone geometry. Br J Radiol 1975; 48: 471-6.

29 Trentham D E, Masi A T. Carpo-metacarpal ratio: a new quantitative measure of radiological progression of wrist involvement in RA. Arthritis Rheum 1976; 19: 939-44.

30 Larsen A, Dale K, Eek M. Radiological evaluation of RA and related conditions by standard reference films. Acta Radiol [Diagn] (Stockh) 1977; 18: 481-91.

31 SAS Institute Inc. Cary N C, ed. SAS user's guide: basics. Version 5. SAS Institute Inc, 1985: 1-1290.

32 SAS Institute Inc. Cary N C, ed. SAS user's guide: statistics. Version 5. SAS Institute Inc, 1985: 1-956.

33 Dixon W J, Brown M B, Engelman J, et al. (eds). BMDP statistics software. Berkeley, LA, London: University of California Press, 1985: 1-733.
34 Joint committee of the medical research council and Nufficld Foundation on clinical trials of cortisone. ACTH. and other therapeutic measures in chronic rheumatic diseases. A comparison of cortisone and aspirin in the treatment of carly cases of rheumatoid arthritis. $\mathrm{Br}$ Med $J$ 1954: i: 1223-7.

35 Pickup M E. Dixon J S. Hallett C. Bird H A. Wright V. Plasma viscosity-a new appraisal of its use as an index of disease activity in RA. Ann Rheum Dis 1981: 40: 271-5.

36 Wright V. Dixon J S. Bird H A. Therapcutic significance of laboratory results in rheumatic diseases. Semin Arthritis Rheum 1985; 15 (suppl 2): 8-13.

37 Scott D L. Symmons D P M. Coulton B L. Popert A J. Longterm outcome of treating rheumatoid arthritis: results after 20 years. Lancet 1987; i: $1108-11$.

38 Devereaux M D. Parr G R. Page Thomas D P. Hazleman B L. Disease activity indexes in RA: a prospective, comparative study with thermography. Ann Rheum Dis 1985; 44: 434-7.

39 Joyce C R B, Hammond K R. Improving clinical judgement. $\mathrm{Br}$ $J$ Rheumatol 1983: 22 (suppl): 14-17.

40 Hart L E. Tugwell P. Buchanan W W. Norman G R. Grace E M. Southwell D. Grading of tenderness as a source of interrater in the Ritchic articular index. $J$ Rheumatol 1985; 12: 716-7.

41 Mielke H. Deicher H. Correlation of inflammatory RA disease activity with laboratory parameters. Scand J Rheumatol 1985; 14: 22-4.

42 Fries J. F Toward an understanding of patient outcome measurement. Arthritis Rheum 1983; 26: 697-704.

43 Capell H A. Can treatment really influence the radiological progression of RA? Br J Rheumatol 1986: 25: 2-6.

44 Buckland-Wright J C. X-Ray assessment of activity in rheumatoid disease. Br J Rheumatol 1983: 22: 3-10.

45 Schorn D. Osteoporosis in the rheumatoid hand: effects of treatment with D-penicillamine and oral gold. $S$ Afr Med J 1983; 63: $121-3$

46 Fries J F. The assessment of disability: From first to future principles. Br J Rheumatol 1983; 22 (suppl): 48-58.

47 Bombardier C. Ware J, Russell I J, et al. Auranofin therapy and quality of life in patients with rheumatoid arthritis. Results of a multicenter trial. Am J Med 1986: 81: 565-78. 